\title{
Pelvic Exenteration: Surgical Approaches
}

\author{
Jin Kim
}

Division of Colorectal Surgery, Department of Surgery, Korea University College of Medicine, Seoul, Korea

Although the incidence of local recurrence after curative resection of rectal cancer has decreased due to the understanding of the anatomy of pelvic structures and the adoption of total mesorectal excision, local recurrence in the pelvis still remains a significant and troublesome complication. While surgery for recurrent rectal cancer may offer a chance for a cure, conservative management, including radiation and chemotherapy, remain widely accepted courses of treatment. Recent improvement in imaging modalities, perioperative care, and surgical techniques, including bone resection and wound coverage, have allowed for reductions in operative mortality, though postoperative morbidity still remains high. In this review, the techniques, including surgical approaches, employed for management of locally recurrent rectal cancer are highlighted.

Keywords: Rectal neoplasms; Local recurrence; Surgical technique; Pelvic anatomy

\section{INTRODUCTION}

Colorectal carcinomas are a major cause of cancer-related deaths in Korea [1]. The incidence of colorectal carcinomas has increased at an alarming rate as the westernized diet has gained popularity. At the same time, surgical treatment for colorectal cancer has also become more common. While surgery is the mainstay of treatment for rectal cancer, local recurrence has been reported to occur in 2.6 to $32 \%$ of surgically treated patients [2-4]. Despite technical improvements including total mesorectal excision (TME) and the addition of neoadjuvant therapies, locoregional recurrence has been found to have an incidence of 6 to $10 \%[5,6]$. Recurrence typically occurs within 2 years after the initial surgery in more than half of patients and within 3 years in $85 \%$ of patients. Without further treatment, this is associated with an exceptionally poor prognosis [7-9], with a median survival time of 6 to 8 months $[5,9-11]$. Recurrent tumors are frequently accompanied by pelvic pain that is poorly controlled by medications, uncontrollable te-

Received: November 23, 2012 - Accepted: December 28, 2012

Correspondence to: Jin Kim, M.D.

Division of Colorectal Surgery, Department of Surgery, Korea University College of Medicine, 73 Inchon-ro, Seongbuk-gu, Seoul 136-705, Korea Tel: +82-2-920-5346, Fax: +82-2-927-8289

E-mail:mrgs@korea.ac.kr

(C) 2012 The Korean Society of Coloproctology

This is an open-access article distributed under the terms of the Creative Commons Attribution NonCommercial License (http://creativecommons.org/licenses/by-nc/3.0) which permits unrestricted noncommercial use, distribution, and reproduction in any medium, provided the original work is properly cited. nesmus, dysuria, fistulous track formation to another pelvic organ, and malodorous discharge. Conservative management, such as radiotherapy or chemoradiotherapy, may increase survival by up to one year, though side effects can be frequent, cumulative, and at times life-threatening $[5,12,13]$. Despite the fact that up to $90 \%$ of patients experience pain relief with treatment, disease regression is rare. The median duration of pain relief after radiotherapy may be as little as four months [13].

Half of patients with recurrent colorectal cancer have tumors that are restricted to the pelvis, and these patients are potentially amenable to curative resection [14-16]. Advances in surgical practices have expanded the options for patients with locally recurrent rectal cancer. In these circumstances, the surgical technique is referred to as pelvic exenteration. Pelvic exenteration is commonly defined as surgery to remove the lower colon, rectum, and bladder, and subsequently to create stomata (openings) through which urine and stool are passed out of the body. In women, the cervix, vagina, ovaries, and nearby lymph nodes are also removed. Most classification systems proposed relate to recurrent rectal cancer, but the principles translate to primary rectal cancer. Pelvic exenterations are classified into five groups: anterior pelvic exenterations, which in addition to the resection of central pelvic organs include removal of the bladder and distal ureters bilaterally; posterior pelvic exenteration (PPE), which involve removal of the central organs together with the rectosigmoid (with or without the anal canal); total pelvic exenterations, a combination of both anterior and PPEs; extended exenterations, which include abdominosacral resection; individualized approaches, such as rectal exci- 
sion with concomitant radical prostatectomy with preservation of the bladder [17]. Complications of pelvic exenteration are more severe than those of standard resection of a colorectal carcinoma, so it is not commonly performed. In this review, the current surgical approaches for radical resection of recurrent rectal cancer are highlighted.

\section{SCHEMATIC ANATOMY OF THE PELVIS}

In order to understand this approach for the treatment of pelvic recurrence, having a good understanding of the complex anatomy of the pelvis is paramount. The pelvis is bounded by the sacrum and coccyx posteriorly and is formed by the ischium and ileum of the hip bone. Identification of the obturator membrane, sacrotuberous and sacrospinous ligaments, obturator internus and piriformis muscles, internal iliac vessels and their corresponding branches and tributaries, and the pelvic portion of the ureter is important in performing pelvic reconstruction operations (Figs. 1 and 2). The obturator membrane is a fibrous membrane that almost entirely covers the obturator foramen between the superior and the inferior pubic rami. In the superior aspect of this membrane is a small gap known as the obturator canal through which the obturator nerve and vessels pass as they exit the pelvis and enter the thigh. The sacrotuberous ligament is a strong ligament that extends from the lateral border of the sacrum, coccyx, and posterior inferior iliac spine into the ischial tuberosity (Fig. 1). The sacrospinous ligament is a strong, triangular-shaped ligament that is attached at its base to the lateral part of the sacrum and coccyx, and extends at its apex into the spine of the ischium (Fig. 1). The main function of these ligaments is to prevent the pelvis from rotating upward along the central axis of the sacroiliac joint under the weight

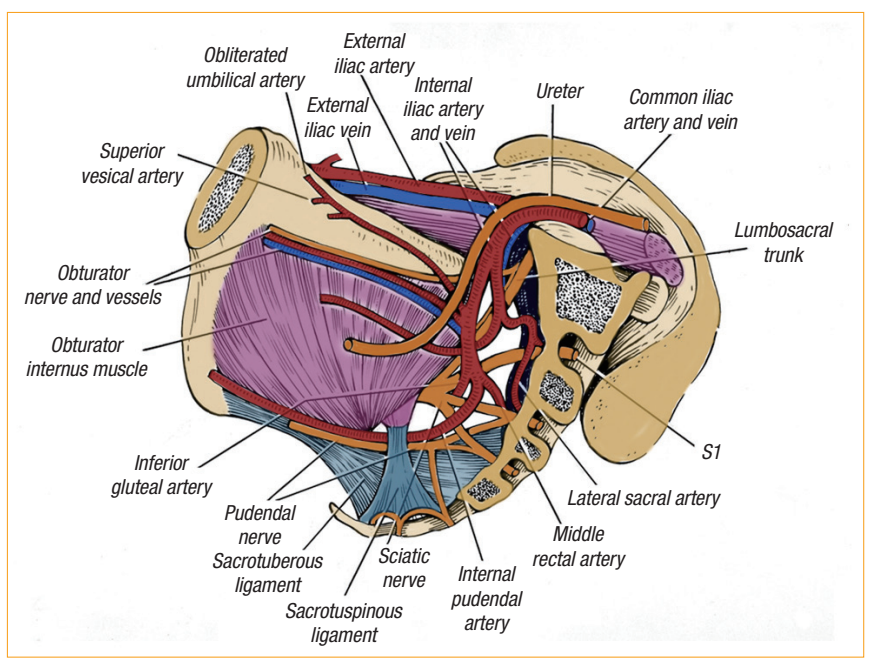

Fig. 1. Schematic illustrations of the complex anatomical structures in the lateral pelvis (modified from Austin and Solomon. Dis Colon Rectum 2009;52:1223-33, with permission of Wolters Kluwer Health [29]). of the body. These ligaments convert the greater and the lesser sciatic notches into the greater and the lesser sciatic foramina. The importance of the greater sciatic foramina is that they provide an exit from the true pelvis into the gluteal region for the sciatic nerves (L4, L5, S1, S2, S3), the pudendal nerves (S2, S3, S4), and the gluteal nerves and vessels. The lesser sciatic foramina provide a window into the perineum from the gluteal region below the pelvic floor (levator ani and coccygeus muscles) for the pudendal nerves and the internal pudendal vessels.

The obturator internus muscle originates from the pelvic surface of the obturator membrane and the adjacent parts of the pelvic bone (superior ramus, inferior ramus, and ischial ramus). The muscle fibers unite to form a tendon that exits the true pelvis through the lesser sciatic foramen and extends into the greater trochanter of the femur. Posterior and lateral to the obturator internus muscle are the nerve roots of the sacral plexus (S1, S2, S3) and the lumbosacral trunk. These nerve roots come together to form the sciatic nerve, which passes through the greater sciatic foramen to enter the gluteal region. Posterior to these nerves is the piriformis muscle, which arises from the front of the lateral masses of the sacrum and leaves the pelvis to enter the gluteal region by passing laterally through the greater sciatic foramen. It then enters the upper border of the greater trochanter of the femur (Fig. 3). The external iliac vessels course along the medial border of the psoas muscle and the curvature of the pelvic inlet. They exit from the pelvis by running under the inguinal ligament, at which point they become the femoral artery. The internal iliac vessels lie deep in the pelvic peritoneum, originating approximately 1 to $2 \mathrm{~cm}$ distal to the sacroiliac joint where the common iliac vessels divide into the external and the internal iliac vessels. These vessels pass medially and inferiorly into the pelvis and to the upper margin of

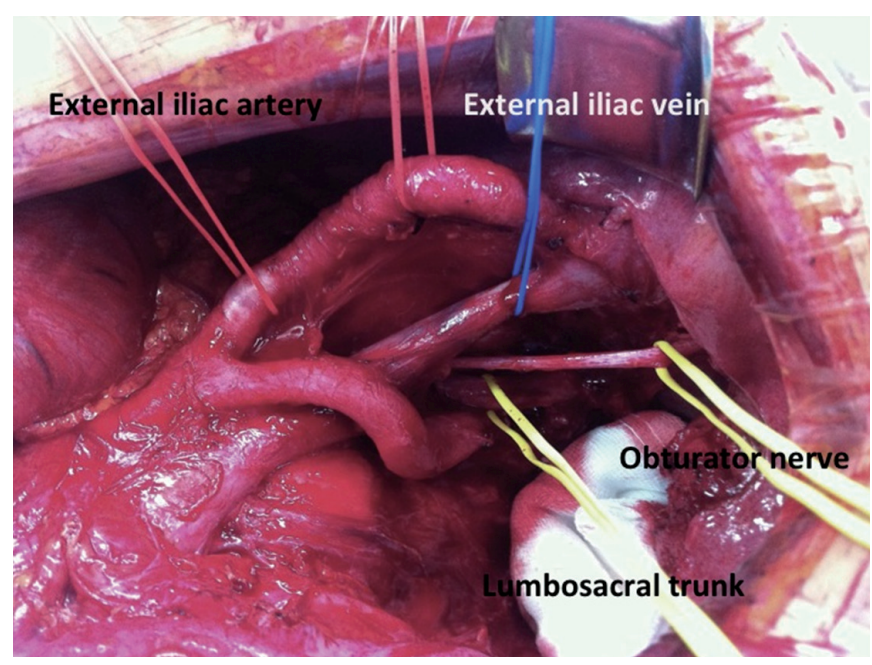

Fig. 2. Illustration of the isolation of the internal and the external iliac arteries, as well as neural structures, of the lateral pelvis by using vessel loops. 


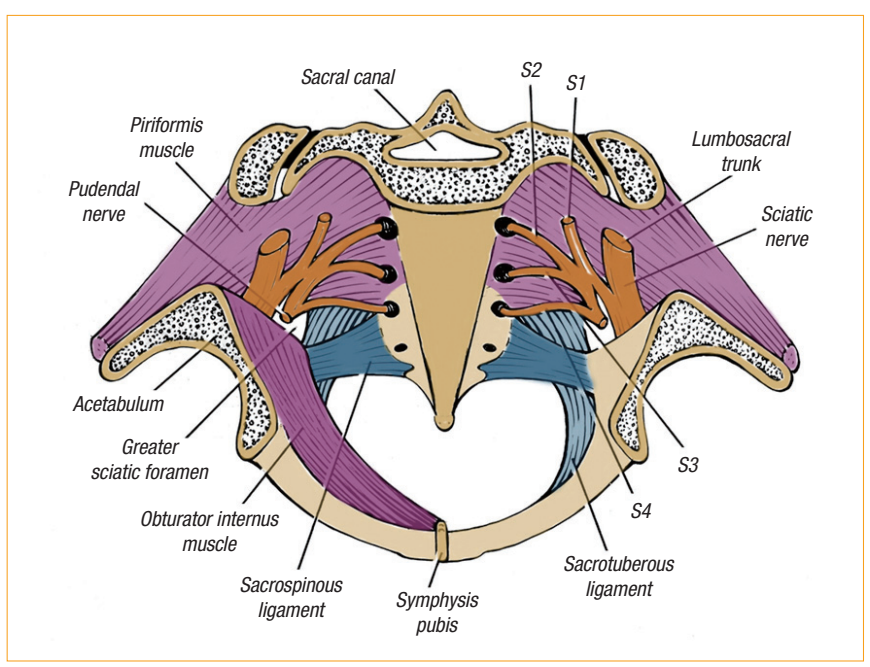

Fig. 3. Schematic illustrations of the pelvic ligaments, muscles, and nerve (modified from Austin and Solomon. Dis Colon Rectum 2009; 52:1223-33, with permission of Wolters Kluwer Health [29]).

the greater sciatic foramen. At this point, they divide into anterior and posterior divisions or tributaries. These branches or tributaries supply and drain blood from the pelvic organs, pelvic sidewalls, buttocks, and perineum. If the branches and tributaries of the internal iliac vessels are to be defined, the overlying pelvic peritoneum must be incised, which is often greatly thickened after neoadjuvant radiotherapy for recurrent or primary cancer.

\section{CLASSIFICATION OF RECURRENCE PATTERNS}

If an operative plan is to be developed, establishing the recurrence pattern is important. Several classifications based on the specific structures that the local recurrence involves, resectability, and the extent of resection needed have been proposed for locally recurrent rectal cancer [18-25]. There are three common types of recurrence that are based on anatomic location. The localized type is confined to the soft tissues within the center of the pelvis. Tumors may recur around the colorectal anastomosis and present with or without invasion of the adjacent urogenital organs. In these cases, the sacrum and the pelvic sidewalls are usually spared. The sacral invasive type involves a recurrent tumor that invades posteriorly into the sacrum. If there is involvement at or below the $S 2 / 3$ junction, a sacrectomy can be performed. The lateral invasion type presents the most technical difficulties and the worst prognosis. Invasion of the pelvic sidewall indicates that the tumor lies close to the main vessels or nerves (Table 1).

\section{PATIENT SELECTION}

Concerns for extensive surgical resection include microscopically clear margins (R0) and acceptable postoperative morbidity and mortality. Patient comorbidities (American Society of Anesthesiologists grade IV/V) may preclude surgery regardless of the potential resectability of the tumor. Resectability should be determined by preoperative imaging including computed tomography (CT), magnetic resonance imaging (MRI), and positron emission tomography (PET) with CT (PET/CT). The presence of unresectable extrapelvic disease on imaging is generally considered to be a contraindication to surgery. Additionally, other various contraindications are applied on a case-by-case basis (Table 2). Patients with systemic metastases are commonly excluded, though selected patients with localized resectable liver or lung metastases may be considered for surgical therapy because a chance exists for cure or palliation $[26,27]$. Factors that contraindicate exenterative surgery include extension through the greater sciatic notch, encasement of the external iliac vessels, paraaortic lymphadenopathy, and lower limb edema indicating venous or lymphatic obstruction [28]. Solomon's unit previously achieved long-term survival with no operative mortality in 36 patients treated with an en bloc lateral pelvic wall dissection with internal and external iliac vascular resection [29]. Although some institutions have reported successful resection of invasive tumors above the level of S2-S3, this is considered to be a relative contraindication to surgery [30]. When possible, tissue diagnosis should be conducted to confirm the presence of the recurrent tumor before proceeding with an extensive surgical resection. If the location of the recurrence or the presence of surrounding fibrosis do not allow for tissue diagnosis, highly convincing radiological evidence for recurrence (PET/CT scan or serial radiologic examinations during follow-up that demonstrate enlargement of the suspected mass) is sufficient for exploration and attempted resection, after frank discussion with the patient as to the risks of the procedure.

\section{SURGICAL APPROACH}

Surgical procedures are classified into radical or extended radical resections. Radical resection is defined as resection that is achieved without the need for removal of another pelvic organ. Extended radical resections involve at least one adjacent pelvic organ, bony structure, or major vessel. The standard steps of these procedures are described below.

\section{Abdominal approach and exploration}

The location of recurrent tumors in patients undergoing pelvic exenteration for recurrent colorectal cancer is varied; thus, the type of surgical procedure used also varies considerably. The procedure typically begins with the abdominal phase (anterior phase) for pelvic dissection and subsequently moves to the sacral phase (posterior phase) for the perineal or sacral resection. A midline laparotomy is used to enter the abdominal cavity, followed by thorough adhesiolysis. The absence of undefined preoperative intra-abdominal metastatic disease should be confirmed at that time. Since R0 resection is the goal of surgery and undiagnosed peritoneal or vis- 
Table 1. Patterns of invasion of locally recurrent rectal cancer

\begin{tabular}{|c|c|c|c|}
\hline Authors/institution & Classification & Description & Note \\
\hline \multirow[t]{4}{*}{ Wanebo et al. [22] } & TR1 or TR2 & $\begin{array}{l}\text { Intraluminal local recurrence at the primary resection site } \\
\text { following local excision or at the anastomosis site }\end{array}$ & \\
\hline & TR3 & $\begin{array}{l}\text { Anastomotic recurrence with full thickness penetration beyond } \\
\text { the bowel wall and into the perirectal soft tissue }\end{array}$ & \\
\hline & TR4 & $\begin{array}{l}\text { Invasion into adjacent organs, including the vagina, uterus, pros- } \\
\text { tate, bladder, and seminal vesicles, or into the presacral tissues } \\
\text { with tethering but not fixation }\end{array}$ & \\
\hline & TR5 & $\begin{array}{l}\text { Invasion of the bony ligamentous pelvis, including the sacrum, } \\
\text { low pelvic/side walls, or sacrotuberous/ischial ligaments }\end{array}$ & \\
\hline Mayo Clinic [23] & F0 to F3 & $\begin{array}{l}\text { Degree of fixation both in terms of site (anterior, sacral, right, or } \\
\text { left) and number of points of fixation }\end{array}$ & $\begin{array}{l}\text { Patients with more extensive } \\
\text { fixation presented later and had } \\
\text { more complications following } \\
\text { repeat resection }\end{array}$ \\
\hline \multirow[t]{3}{*}{ Yamada et al. [24] } & Localized type & $\begin{array}{l}\text { Recurrent tumor is localized to adjacent pelvic organs or connec- } \\
\text { tive tissue }\end{array}$ & $\begin{array}{l}\text { The pattern of invasion was a } \\
\text { significant prognostic factor, with } \\
5 \text {-year survival rates of } 38 \% \text { for } \\
\text { localized, } 10 \% \text { for sacral, and } 0 \% \\
\text { for lateral }\end{array}$ \\
\hline & Sacral invasive type & $\begin{array}{l}\text { Recurrent tumor invades the lower sacrum }(\mathrm{S} 3, \mathrm{~S} 4, \mathrm{~S} 5) \text {, coccyx, } \\
\text { or periosteum }\end{array}$ & \\
\hline & Lateral invasive type & $\begin{array}{l}\text { Recurrent tumor invades the sciatic nerve, greater sciatic fora- } \\
\text { men, lateral pelvic wall, or upper sacrum }(S 1, S 2)\end{array}$ & \\
\hline \multirow[t]{4}{*}{ Memorial Sloan Kettering [25] } & Anterior & $\begin{array}{l}\text { Anastomotic, mesorectal or perirectal soft tissue, or perineum } \\
\text { following abdominoperineal excision of rectum }\end{array}$ & \\
\hline & Posterior & $\begin{array}{l}\text { Genitourinary tract, including the bladder, vagina, uterus, seminal } \\
\text { vesicles, and prostate }\end{array}$ & \\
\hline & Lateral & Sacrum and presacral fascia & \\
\hline & Axial & Soft tissues of the pelvic sidewall and lateral bony pelvis & \\
\hline \multirow[t]{4}{*}{ Boyle et al. [19] } & Central & $\begin{array}{l}\text { Tumor restricted to the pelvic organs without invasion into the } \\
\text { bone or the sidewalls of the pelvis }\end{array}$ & \\
\hline & Sacral & $\begin{array}{l}\text { Tumor is present in the presacral space and invades into the sa- } \\
\text { crum }\end{array}$ & \\
\hline & Sidewall of the pelvis & $\begin{array}{l}\text { Tumor on the lateral pelvic sidewall with or without extension } \\
\text { through the greater sciatic foramen and/or the piriformis and } \\
\text { gluteal region }\end{array}$ & \\
\hline & Composite & Sacral and sidewall recurrence combined & \\
\hline
\end{tabular}

ceral metastases are often unresectable, definitive surgery should be avoided in these cases. When making the incision, the surgeon must take care not to injure the inferior epigastric artery in order to preserve the blood supply to the rectus muscle, which can later be used as a myocutaneous flap. The cecum and the small bowel are mobilized to facilitate the approach into the pelvis, as well as ureteral dissection. The small bowel is usually attached to the previous operative surface of dissection, the presacral area, or the recurrent tumor. If the small bowel is attached to the recurrent tumor, it should be resected en bloc to achieve curative resection.

\section{Identification of ureters}

The ureter is often located medially in patients who have previously undergone surgery. Preoperative placement of ureteral stents is helpful in locating and avoiding unintended damage to the ureters. The course of the distal pelvic ureter is confirmed by sharp dissection, and its relationship to the tumor may be identified by inspection and palpation. If one or both ureters are involved, the surgeon may attempt re-implantation into the bladder or construct an ileal or colonic conduit with a radical cystectomy. If the decision is made to proceed with a radical cystectomy, the ureters are not transected until later in the procedure. If no evidence of ureteral involvement exists, unilateral or bilateral ureterolysis is per- 
Table 2. Contraindications for radical surgery

\begin{tabular}{|c|c|c|}
\hline Authors & Absolute contraindications & Relative contraindications \\
\hline \multirow[t]{4}{*}{ Boyle et al. [19] } & Encasement of external iliac vessels ${ }^{a}$ & Distant metastases \\
\hline & Extension of tumor through the sciatic notch ${ }^{\mathrm{a}}$ & Primary stage IV disease \\
\hline & Poor performance status & Inability to achieve $\mathrm{R} 0$ resection \\
\hline & & Sacral invasion above S2/3 \\
\hline \multirow{5}{*}{ Pawlik et al. [26] } & Involvement of common or external iliac vessels ${ }^{\mathrm{a}}$ & \\
\hline & Para-aortic lymph node metastases & Significant medical comorbidity \\
\hline & Involvement of sacrum above S1 & Poor performance status/inability to care for stomas \\
\hline & Tumor extension through the sciatic foramen ${ }^{a}$ & \\
\hline & Pelvic side wall involvement ${ }^{\mathrm{a}}$ & \\
\hline
\end{tabular}

aMay be considered as relative contraindications by the supporting data.

formed from the pelvic brim to the bladder. Once the pelvic ureters are mobilized, a vessel sling is placed around each one so that they can be easily identified throughout the procedure. The left colon is also mobilized and transected at the appropriate level for subsequent end-colostomy and/or urinary conduit construction. Deep pelvic dissection into the presacral space is then conducted posteriorly along the lower aorta and continued distally over the iliac vessels and ureters.

\section{Vascular approach}

Vascular exposure often requires mobilization of the lower aorta and vena cava, in addition to the iliac arteries and veins. Circumferential mobilization of the common and the external iliac arteries may be needed to facilitate exposure of the veins. First, the internal iliac artery and its branches are ligated and divided distal to the takeoff of the posterior division of the superior gluteal artery branch. This is sometimes done to conserve blood flow to the gluteal flaps. At the level of the aortic bifurcation, lymph node dissection, including the nodes overlying the aortoiliac bifurcation, common iliac, and external iliac vessels, is performed until the origin of the internal iliac vessels is reached. The nodal tissue around the internal iliac territory is not dissected, but is taken en bloc later in the procedure. Multiple internal iliac vein branches are ligated after control of the main trunk of the internal iliac vein is achieved. The branches are ligated and divided before ligation of the main trunk to avoid venous distension of the branches, which can cause bleeding. The lateral and the middle sacral vein branches, which drain into the posterior aspect of the left common iliac vein and caval confluence, are then ligated and divided. Metallic clip or suture ligation may be used for branches, and vascular staplers can be used for the trunk of the internal iliac vessels. The vascular dis- section is conducted along both sides of the sacrum onto the pelvic floor. The anterior lines of resection are delineated, and the involved structures and pelvic organs are mobilized widely for subsequent en bloc resection. During this abdominal approach, a colostomy and an ileal or colonic urinary conduit are fashioned as needed. A vertical rectus abdominis myocutaneous (VRAM) flap is then prepared for subsequent perineal reconstruction before closing the abdomen with the aid of a plastic surgeon.

\section{Posterior (sacral) approach}

Prior to positioning the patient in the prone position, a thick silastic film or gauze is placed anterior to the sacrum and posterior to the vessels and soft-tissue structures to protect them against injury when blind osteotomies are performed during the sacral or posterior portion of the procedure. The sacral level of transection for anterior osteotomies is determined by marking the area with screws and intraoperative fluoroscopy. During this process, the surgeon must take care not to cause injury to the thecal sac. In the posterior approach, the screw marks the level of the osteotomy (as visualized with lateral fluoroscopy) to facilitate joining to the anterior unicortical osteotomy. If lateral (vertical) osteotomies are necessary through the ilium, these are performed from the anterior approach. The roof of the sciatic notch is identified (with the sciatic nerve and gluteal vessels protected), and a diamond burr is used to perform the osteotomy. Care must be taken in orienting this correctly, given the oblique nature of the sacroiliac joints.

\section{Posterior (sacral) or perineal approach}

The sacral or posterior phase is carried out with the patient in the prone position. A posterior midline incision is made along the vertical midline of the sacrum extending from the 5 th lumbar 
Table 3. Management of persistent pelvic bleeding

\begin{tabular}{|c|c|}
\hline Methods for bleeding control & Note \\
\hline Packing & Classical method, but has the disadvantage of reoperation for removal of packing and risk of re-bleeding \\
\hline \multirow[t]{3}{*}{ Thumbtack } & $\begin{array}{l}\text { Not readily performed at all institutions, and cannot be applied either to bleeding points originating from } \\
\text { the sacral neural foramen or near vital structures such as the ureters }\end{array}$ \\
\hline & Ineffective for diffuse hemorrhage \\
\hline & Displacement resulting in chronic pain, anastomotic disruption, and anastomotic fistula \\
\hline Pledgets suture with various materials & Mesh plugs, muscle fragment \\
\hline \multirow[t]{3}{*}{ Local hemostatic agents } & FloSeal; Baxter, Deerfield, IL, USA \\
\hline & Surgicel Fibrillar; Ethicon, Somerville, NJ, USA \\
\hline & Gelfoam; Baxter, Deerfield, IL, USA \\
\hline \multirow[t]{4}{*}{ Energy instruments ${ }^{\mathrm{a}}$} & Diathermy \\
\hline & Argon beam \\
\hline & Harmonic scalpel; Ethicon, Somerville, NJ, USA \\
\hline & Ligasure; Covidien, Mansfield, MA, USA \\
\hline
\end{tabular}

a Some authors do not recommend coagulating with an energy device because it may worsen bleeding.

vertebra to the perineal scar or the anus. The gluteus maximus muscles are subsequently dissected away from the sacral attachments, and the sacrospinous and sacrotuberous ligaments are divided to access the pelvic cavity posteriorly. The piriformis muscle is divided while taking care to protect the sciatic and the pudendal nerves. A laminectomy, dural sac ligation, and sacral resection are then carried out. Lateral fluoroscopy is used to visualize the screw marking the level of the anterior osteotomy and to guide the final osteotomies. The posterior wound may be reconstructed with a pedicled myocutaneous rectus flap, which will be discussed in detail below.

\section{CONTROL OF BLEEDING}

Bleeding during pelvic exenteration typically originates in the presacral plexus or the internal iliac vein, and is a common and potentially life-threatening complication. The incidence of presacral bleeding has been reported to be 3 to $9.4 \%$, but is more frequent in patients who have undergone radiation therapy or previous rectal surgery [31]. The presacral venous plexus runs into the pelvic fascia covering the anterior aspect of the sacrum. It is formed by the two lateral sacral veins, the middle sacral vein, and communicating veins. These veins are avalvular and communicate via the basivertebral veins within the internal vertebral venous system [32]. When the patient is in the lithotomy position, hydrostatic pressure is increased two- to threefold compared with the pressure in the inferior vena cava [33]. These high-pressure venous bleeders can be very difficult to control with conventional measures, such as suturing, clipping, and electrocautery, because the adventitia of the sacral basivertebral veins is fixed to the sacral periosteum at the margins of the sacral foramina. Bleeding should be controlled by applying pressure to the source, and the optimal field of view should be obtained by lengthening the incision and using additional retractors. Additionally, packing with gauze for approximately 10 minutes can help to control the hemorrhage or to visualize the source of bleeding. The packed gauze should be removed cautiously after moistening with saline to avoid disruption of the newly formed clot. If this technique fails, several other options are available for management of presacral venous bleeding (Table 3).

\section{WOUND COVERAGE}

While small defects can be closed directly, large wound defects frequently occur when a wide range of perineal surgeries are combined. Perineal wound closure after radical surgery for locally recurrent rectal cancer is associated with a high wound complication rate, estimated at 40 to $50 \%$ [34]. These wounds can be covered using several methods to prevent infectious complications and exposure of the internal structures. Myocutaneous flaps play a large role in pelvic reconstruction after radical resection of malignant disease, particularly when the patient must undergo total pelvic irradiation. These flaps offer the advantage of using nonirradiated 


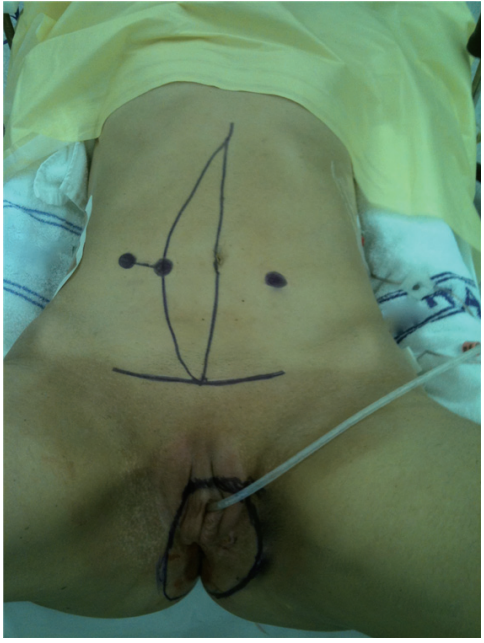

Fig. 4. Unilateral gluteus maximus myocutaneous $\mathrm{V}$-Y advancement flap used to cover the sacral wound.

tissue and blood supply for coverage of the defects. Transpelvic VRAM flaps, bilateral gluteal advancement or rotation flaps, and posterior thigh flaps or free flaps are recommended for reconstruction [35].

The rectus abdominis muscle has a unique blood supply from the inferior epigastric vessels, and the anatomy of these vessels allows for the flap to be based on a long muscle pedicle with excellent blood supply. The VRAM flap has the smallest incidence of necrosis of any of the myocutaneous flaps associated with reconstructive wound coverage. Patients undergoing reconstructive surgery will typically require stomas, which should be considered prior to reconstruction so as not to interrupt their location (Fig. 4).

To prevent interruption of the inferior epigastric vessels, the surgeon should take care when making the primary incision and conducting the anterolateral pelvic dissection. When enough skin is present to cover the posterior wound, a V-Y flap may be constructed using the gluteal muscles (Fig. 5). The addition of an omentoplasty on the left gastroepiploic pedicle helps to reduce dead space and may improve perineal wound healing and reduce the duration of pelvic drainage. Additionally, another reconstructive option was reported that utilized the sigmoid colon [36].

\section{CONCLUSION}

A proportion of patients who undergo successful TME with or without preoperative radiotherapy will develop local recurrence. Approximately half of these patients will have an isolated local recurrence without systemic or disseminated disease. Radiotherapy and chemotherapy may provide palliation for patients with local recurrence, but may also result in significant morbidity with little chance for a cure. Surgery for local recurrence has been established as the only treatment that offers a realistic chance of long-term survival. While surgical intervention may be associated with significant morbidity, careful patient selection and the use of multimodal therapy can result in a 5-year survival of up to $35 \%$ and an

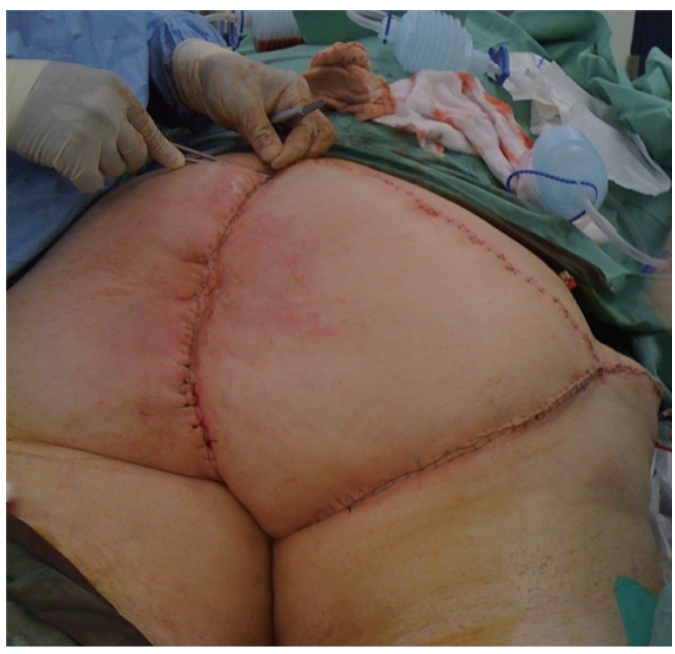

Fig. 5. Preoperative design for the vertical rectus abdominis myocutaneous flap. The location of the urinary conduit and colostomy should be marked carefully prior to the operation.

improved quality of life in patients undergoing an R0 resection. Therefore, current data indicate that radical surgery with a multidisciplinary approach remains the only treatment option that improves both survival rates and local control.

\section{CONFLICT OF INTEREST}

No potential conflict of interest relevant to this article was reported.

\section{REFERENCES}

1. National Cancer Information Center. Cancer information service [Internet]. Goyang (KR): National Cancer Information Center; c2011 [cited 2012 Jun 5]. Available from: http://www.cancer. go.kr/ncic/cics_f/01/014/index.html.

2. Heald RJ, Moran BJ, Ryall RD, Sexton R, MacFarlane JK. Rectal cancer: the Basingstoke experience of total mesorectal excision, 1978-1997. Arch Surg 1998;133:894-9.

3. Abulafi AM, Williams NS. Local recurrence of colorectal cancer: the problem, mechanisms, management and adjuvant therapy. $\mathrm{Br}$ J Surg 1994;81:7-19.

4. Heriot AG, Kumar D. Rectal cancer recurrence : factors and mechanisms. Colorectal Dis 2000;2:126-36.

5. Bakx R, Visser O, Josso J, Meijer S, Slors JF, van Lanschot JJ. Management of recurrent rectal cancer: a population based study in greater Amsterdam. World J Gastroenterol 2008;14:6018-23.

6. Sebag-Montefiore D, Stephens RJ, Steele R, Monson J, Grieve R, Khanna S, et al. Preoperative radiotherapy versus selective postoperative chemoradiotherapy in patients with rectal cancer (MRC CR07 and NCIC-CTG C016): a multicentre, randomised trial. Lancet 2009;373:811-20.

7. Ogunbiyi OA, McKenna K, Birnbaum EH, Fleshman JW, Kodner 
IJ. Aggressive surgical management of recurrent rectal cancer--is it worthwhile? Dis Colon Rectum 1997;40:150-5.

8. Heriot AG, Byrne CM, Lee P, Dobbs B, Tilney H, Solomon MJ, et al. Extended radical resection: the choice for locally recurrent rectal cancer. Dis Colon Rectum 2008;51:284-91.

9. Palmer G, Martling A, Cedermark B, Holm T. A population-based study on the management and outcome in patients with locally recurrent rectal cancer. Ann Surg Oncol 2007;14:447-54.

10. Gunderson LL, Sosin H. Areas of failure found at reoperation (second or symptomatic look) following "curative surgery" for adenocarcinoma of the rectum. Clinicopathologic correlation and implications for adjuvant therapy. Cancer 1974;34:1278-92.

11. Wanebo HJ, Koness RJ, Vezeridis MP, Cohen SI, Wrobleski DE. Pelvic resection of recurrent rectal cancer. Ann Surg 1994;220: 586-95.

12. Wong CS, Cummings BJ, Brierley JD, Catton CN, McLean M, Catton $\mathrm{P}$, et al. Treatment of locally recurrent rectal carcinoma: results and prognostic factors. Int J Radiat Oncol Biol Phys 1998; 40:427-35.

13. Ito Y, Ohtsu A, Ishikura S, Boku N, Nihei K, Ogino T, et al. Efficacy of chemoradiotherapy on pain relief in patients with intrapelvic recurrence of rectal cancer. Jpn J Clin Oncol 2003;33:180-5.

14. Rao AR, Kagan AR, Chan PM, Gilbert HA, Nussbaum H, Hintz BL. Patterns of recurrence following curative resection alone for adenocarcinoma of the rectum and sigmoid colon. Cancer 1981; 48:1492-5.

15. Pilipshen SJ, Heilweil M, Quan SH, Sternberg SS, Enker WE. Patterns of pelvic recurrence following definitive resections of rectal cancer. Cancer 1984;53:1354-62.

16. McDermott FT, Hughes ES, Pihl E, Johnson WR, Price AB. Local recurrence after potentially curative resection for rectal cancer in a series of 1008 patients. Br J Surg 1985;72:34-7.

17. Nguyen DQ, McGregor AD, Freites O, Carr ND, Beynon J, ElSharkawi AM, et al. Exenterative pelvic surgery: eleven year experience of the Swansea Pelvic Oncology Group. Eur J Surg Oncol 2005;31:1180-4.

18. Hahnloser D, Nelson H, Gunderson LL, Hassan I, Haddock MG, O'Connell MJ, et al. Curative potential of multimodality therapy for locally recurrent rectal cancer. Ann Surg 2003;237:502-8.

19. Boyle KM, Sagar PM, Chalmers AG, Sebag-Montefiore D, Cairns A, Eardley I. Surgery for locally recurrent rectal cancer. Dis Colon Rectum 2005;48:929-37.

20. Suzuki K, Dozois RR, Devine RM, Nelson H, Weaver AL, Gunderson LL, et al. Curative reoperations for locally recurrent rectal cancer. Dis Colon Rectum 1996;39:730-6.

21. Moore HG, Shoup M, Riedel E, Minsky BD, Alektiar KM, Ercolani $\mathrm{M}$, et al. Colorectal cancer pelvic recurrences: determinants of resectability. Dis Colon Rectum 2004;47:1599-606.
22. Wanebo HJ, Antoniuk P, Koness RJ, Levy A, Vezeridis M, Cohen SI, et al. Pelvic resection of recurrent rectal cancer: technical considerations and outcomes. Dis Colon Rectum 1999;42:1438-48.

23. Suzuki K, Gunderson LL, Devine RM, Weaver AL, Dozois RR, Ilstrup DM, et al. Intraoperative irradiation after palliative surgery for locally recurrent rectal cancer. Cancer 1995;75:939-52.

24. Yamada K, Ishizawa T, Niwa K, Chuman Y, Akiba S, Aikou T. Patterns of pelvic invasion are prognostic in the treatment of locally recurrent rectal cancer. Br J Surg 2001;88:988-93.

25. Guillem J, Ruo L. Strategies in operative therapy for locally recurrent rectal cancer. Semin Colon Rectal Surg 1998;9:259-68.

26. Pawlik TM, Skibber JM, Rodriguez-Bigas MA. Pelvic exenteration for advanced pelvic malignancies. Ann Surg Oncol 2006;13: 612-23.

27. Mirnezami AH, Sagar PM, Kavanagh D, Witherspoon P, Lee P, Winter D. Clinical algorithms for the surgical management of locally recurrent rectal cancer. Dis Colon Rectum 2010;53:1248-57.

28. Moriya Y, Akasu T, Fujita S, Yamamoto S.Total pelvic exenteration with distal sacrectomy for fixed recurrent rectal cancer inthe pelvis. Dis Colon Rectum. 2004 ; 47:2047-53.

29. Austin KK, Solomon MJ. Pelvic exenteration with en bloc iliac vessel resection for lateral pelvic wall involvement. Dis Colon Rectum 2009;52:1223-33.

30. Dozois EJ, Privitera A, Holubar SD, Aldrete JF, Sim FH, Rose PS, et al. High sacrectomy for locally recurrent rectal cancer: Can long-term survival be achieved? J Surg Oncol 2011;103:105-9.

31. van der Vurst TJ, Bodegom ME, Rakic S. Tamponade of presacral hemorrhage with hemostatic sponges fixed to the sacrum with endoscopic helical tackers: report of two cases. Dis Colon Rectum 2004;47:1550-3.

32. Baque P, Karimdjee B, Iannelli A, Benizri E, Rahili A, Benchimol $D$, et al. Anatomy of the presacral venous plexus: implications for rectal surgery. Surg Radiol Anat 2004;26:355-8.

33. Wang QY, Shi WJ, Zhao YR, Zhou WQ, He ZR. New concepts in severe presacral hemorrhage during proctectomy. Arch Surg 1985;120:1013-20.

34. Bullard KM, Trudel JL, Baxter NN, Rothenberger DA. Primary perineal wound closure after preoperative radiotherapy and abdominoperineal resection has a high incidence of wound failure. Dis Colon Rectum 2005;48:438-43.

35. Butler CE, Gundeslioglu AO, Rodriguez-Bigas MA. Outcomes of immediate vertical rectus abdominis myocutaneous flap reconstruction for irradiated abdominoperineal resection defects. J Am Coll Surg 2008;206:694-703.

36. Sahakitrungruang C, Atittharnsakul P. Sigmoid flap: a novel technique for perineal and neovaginal reconstruction after abdominoperineal resection with near total vaginectomy for locally advanced rectal cancer. J Am Coll Surg 2010;210:e5-8. 